\section{Direito e Saúde: A Medida de Segurança sob a Perspectiva Bioética}

\section{Menegaz, Mariana Lima}

Mestranda em Direito pela Universidade Estadual de São Paulo "Júlio Mesquita Filho" - UNESP; bolsista CAPES; Especialização em Processo Civil e Argumentação Jurídica pela Pontifícia Universidade Católica de Minas Gerais PUC Minas; mediadora e conciliadora judicial $e$ extrajudicial, com pelo CEBRAMAR/DF. E-mail: mariana_menegaz@hotmail.com

\section{Marchetto, Patrícia Borba}

Doutora em Direito pela Universidade de Barcelona. Professora do curso de Administração Pública da FCL, UNESP. Professora do programa de pós-graduação em Direito $d a \quad F C H S, \quad$ UNESP. E-mail: pmarchetto@fclar.unesp.br.

PALAVRAS-CHAVE: Bioética, Medida de Segurança, Manicômio Judicial, Reforma Psiquiátrica.

O presente trabalho analisa os aspectos bioéticos da aplicação da Medida de Segurança aos agentes portadores de doença mental, considerados inimputáveis no âmbito penal. Verifica-se, primeiramente, a problemática existente quanto ao prazo para cumprimento desta sanção, em razão da omissão legal acerca do tempo máximo de sua execução. $\mathrm{O}$ artigo 26, do Código Penal, determina a não aplicação de pena para o agente que for, ao tempo da ação ou da omissão, inteiramente incapaz de entender o caráter ilícito do fato praticado, ou não determinar-se conforme este entendimento, em razão de doença mental ou desenvolvimento mental incompleto ou retardado. Ainda neste Código, é indicado apenas tempo máximo de cumprimento para as penas privativas de liberdade (artigo 75), que não pode ser superior a trinta anos, porém, silencia sobre a Medida de Segurança. Ocorre que a Constituição Federal de 1988, no artigo 5 XLVIII, proíbe a prisão com caráter perpétuo, porém, os Tribunais brasileiros entendem de forma divergente sobre o tema, pois o Supremo Tribunal Federal determina que o limite temporal para a execução da sanção seja de trinta anos, ao passo que o Superior Tribunal de Justiça afirma que a duração deve ser limitada conforme o prazo estabelecido para a pena cominada ao delito praticado, evidenciando a controversia existente sobre o presente assunto. A pesquisa ainda analisa os aspectos bioéticos sobre os locais para a execução da Medida de Segurança, iniciando pela retomada histórica dos estabelecimentos em que ela é executa, muita das vezes sendo locais inapropriados, como as próprias penitenciárias. Além disso, há casos em que os individuos são esquecidos e permanecem por longos prazos em hospitais psiquiátricos (inclusive por período superior a trinta anos), sem infra-estrutura e atendimento adequado. Nesse sentido, a
Lei $\mathrm{n}^{\mathrm{o}} \quad 10.216 / 2001$ (Lei Antimanicomial), objetiva reorganizar o setor da saúde e da assistência psiquiátrica do Brasil, com o fim dos Manicômios Judiciais e a adoção de um cuidado integral do indivíduo, através de auxílio multiprofissional para o paciente e para sua familia. Ademais, ressalta-se a importancia da aplicação dos principios bioéticos, tais como o Princípio da Autonomia, principalmente quanto às questões relacionadas ao tratamento imposto ao agente, que corrobora com o Princípio da Beneficiência, ao ser imprescindível um tratamento por equipe especializada e multidisciplinar, objetivando a cura ou melhora do paciente. Ademais, o Princípio da Nãomaleficiência determina que o médico deve causar o mínimo de prejuízo ao paciente e à sua saúde. Isto confirma todo o exposto na pesquisa, pois o tratamento imposto deve objetivar a recuperação e restabelecimento da saúde mental do paciente. Para a realização do trabalho, foi utilizado o método dedutivo, com análise bibliográfica sobre o tema e observancia jurisprudencial dos principais Tribunais brasileiros. Os resultados obtidos demonstram a necessidade de determinação de lapso temporal máximo para a execução desta sanção, além de ser imprescindível a aplicação da Reforma Psiquiátrica. Conclui-se, assim pela a importancia da análise bioética da execução desta sanção, uma vez que o tratamento ao doente mental deve ser multidisciplinar, assegurando todos os direitos e garantias fundamentais do indivíduo.

AGRADECIMENTOS. Agradecemos à Faculdade de Ciências Humanas e Sociais (UNESP - Franca), e também à Coordenação de Aperfeiçoamento de Pessoal de Nível Superior (CAPES). O presente trabalho foi realizado com apoio da Coordenação de Aperfeiçoamento de Pessoal de Nível Superior - Brasil (CAPES) - Código de Financiamento 001 .

\section{REFERÊNCIAS}

[1] ABSALLA, Elias; SOUZA, Patrícia Abdalla de. Bioética, Psiquiatria Forense e a aplicação da Medida de Segurança no Brasil. Revista Bioética 200917 (2): 181 - 190. Disponível em: < http://revistabioetica.cfm.org.br/index.php/revista bioetica/article/vi ew/160 >Acesso em: 17 jan. 2017.

[2] ARBEX, Daniela. Holocausto brasileiro. 1. ed. São Paulo: Geração,2013.

[3] BRASIL. Supremo Tribunal Federal. Habeas Corpus n. ${ }^{\circ} 84219$ SP - Relator Marco Aurélio - Data de Julgamento: 16/08/2005 Primeira Turma - Data de Publicação: DJ 23-09-2005. Disponível em: $<$ http://stf.jusbrasil.com.br/jurisprudencia/763647/habeascorpus-hc-84219-sp>. Acesso em: 25. Set. 2018.

[4] BRASIL. Superior Tribunal de Justiça. Habeas Corpus n. ${ }^{\circ}$ 269377 AL 2013/0124571-2 - Relator Ministro Rogerio Schietti Cruz - Data de Julgamento: 02/10/2014 - Sexta Turma - Data de Publicação: DJe 13/10/2014. Disponível em:

$<$ http://stj.jusbrasil.com.br/jurisprudencia/153309534/habeascorpus-hc-269377-al-2013-0124571-2>. Acesso em: 25. Set. 2018. 
[5] GOFFMAN, Erving. Trad. LEITE, Dante Moreira; DE SOUZA,

Antenor Celestino. Manicômios, prisões e conventos. São Paulo:

Perspectiva, 1974. 